\title{
Sulforaphane counteracts aggressiveness of pancreatic cancer driven by dysregulated Cx43-mediated gap junctional intercellular communication
}

\author{
Tobias Forster ${ }^{1,2, *}$, Vanessa Rausch ${ }^{1,2, *}$, Yiyao Zhang, Orkhan Isayev ${ }^{1,2}$, Katharina \\ Heilmann ${ }^{3}$, Frank Schoensiegel ${ }^{1,2}$, Li Liu ${ }^{1,2}$, Michelle Nessling ${ }^{4}$, Karsten Richter ${ }^{4}$, \\ Sabrina Labsch ${ }^{1,2}$, Clifford C. Nwaeburu ${ }^{1,2}$, Juergen Mattern ${ }^{1,2}$, Jury Gladkich ${ }^{1,2}$, \\ Nathalia Giese ${ }^{2}$, Jens Werner ${ }^{2}$, Peter Schemmer ${ }^{2}$, Wolfgang Gross ${ }^{1,2}$, Martha M. \\ Gebhard $^{1,2}$, Clarissa Gerhauser ${ }^{3}$, Michael Schaefer ${ }^{1,2}$, Ingrid Herr ${ }^{1,2}$ \\ ${ }^{1}$ General, Visceral and Transplantation Surgery, University of Heidelberg, Heidelberg, Germany \\ 2 Experimental Surgery, University of Heidelberg, Heidelberg, Germany \\ ${ }^{3}$ Epigenomics and Cancer Risk Factors, German Cancer Research Center (DKFZ), Heidelberg, Germany \\ ${ }^{4}$ Core Facility Electron Microscopy, German Cancer Research Center (DKFZ), Heidelberg, Germany \\ * These authors contributed equally to this work \\ Correspondence to: Ingrid Herr, email: i.herr@dkfz.de \\ Keywords: Cancer Stem Cells, Pancreatic Cancer, Bioactive dietary agents, Sulforaphane \\ Received: January 3,2014 Accepted: January 20,2014 Published: January 22, 2014
}

This is an open-access article distributed under the terms of the Creative Commons Attribution License, which permits unrestricted use, distribution, and reproduction in any medium, provided the original author and source are credited.

\section{ABSTRACT:}

The extreme aggressiveness of pancreatic ductal adenocarcinoma (PDA) has been associated with blocked gap junctional intercellular communication (GJIC) and the presence of cancer stem cells (CSCs). We examined whether disturbed GJIC is responsible for a CSC phenotype in established and primary cancer cells and patient tissue of PDA using interdisciplinary methods based in physiology, cell and molecular biology, histology and epigenetics. Flux of fluorescent dyes and gemcitabine through gap junctions (GJs) was intact in less aggressive cells but not in highly malignant cells with morphological dysfunctional GJs. Among several connexins, only Cx43 was expressed on the cell surface of less aggressive and GJIC-competent cells, whereas Cx43 surface expression was absent in highly malignant, E-cadherin-negative and GJIC-incompetent cells. The levels of total Cx43 protein and Cx43 phosphorylated at Ser368 and Ser279/282 were high in normal tissue but low to absent in malignant tissue. si-RNA-mediated inhibition of Cx43 expression in GJIC-competent cells prevented GJIC and induced colony formation and the expression of stem cell-related factors. The bioactive substance sulforaphane enhanced Cx43 and E-cadherin levels, inhibited the CSC markers C-Met and CD133, improved the functional morphology of GJs and enhanced GJIC. Sulforaphane altered the phosphorylation of several kinases and their substrates and inhibition of GSK3, JNK and PKC prevented sulforaphaneinduced CX43 expression. The sulforaphane-mediated expression of Cx43 was not correlated with enhanced Cx43 RNA expression, acetylated histone binding and Cx43 promoter de-methylation, suggesting that posttranslational phosphorylation is the dominant regulatory mechanism. Together, the absence of Cx43 prevents GJIC and enhances aggressiveness, whereas sulforaphane counteracts this process, and our findings highlight dietary co-treatment as a viable treatment option for PDA. 


\section{INTRODUCTION}

Pancreatic ductal adenocarcinoma (PDA) is one of the most aggressive malignancies and is typically diagnosed in an advanced state [1]. Gemcitabine is the standard therapy for advanced pancreatic cancer [2] but neither gemcitabine nor the newer FOLFIRINOX combination therapy do not directly target cancer stem cell (CSC) pathways responsible for growth, metastasis, high resistance toward current cancer therapeutics and relapse [3-5].

The mustard oil sulforaphane, which is present in high concentrations in broccoli and its sprouts [6], has well-documented cancer preventive efficacy and was recently shown to inhibit histone deacetylases (HDACs) [7]. Our recent results demonstrated that sulforaphane sensitizes pancreatic CSCs to chemotherapy by inhibiting their self-renewal potential, apoptosis resistance and NF$\kappa \mathrm{B}$ activity [8-11]. Based on several promising animal and epidemiological studies, prospective clinical trials with sulforaphane-enriched broccoli sprout extracts are ongoing in the U.S. to examine the effect on atypical nevi, bladder and prostate cancer [12], and a pilot study recently began at our clinic to evaluate the effect of this nutritional strategy on patients with advanced PDA.

The inhibition of gap junctional intercellular communication (GJIC) may be involved in the autonomous behavior of CSCs, because GJIC confers features absent in stem cells, namely contact inhibition [13], apoptosis sensitivity [14] and terminal differentiation [15]. Gap junctions (GJs) are channels in the plasma membrane that allow direct communication between cells by the passive transport of small molecules and ions [16]. Gemcitabine and other chemotherapeutics also diffuse from cell-tocell via GJs [17], and this so-called "bystander effect" leads to a higher cellular concentration of cytotoxic agents [18]. GJs are formed by a family of more than 20 different connexins, and altered connexin expression is involved in carcinogenesis and therapy resistance [19]. The absence of GJs is a common feature of pluripotent stem cells. However, cells derived from stem cells, e.g., progenitor cells, have functional GJs, suggesting that GJIC develops during differentiation [20-22]. Recently, in human spheroidal glioma cultures, reduced GJIC and very low levels of $\mathrm{Cx} 43$ were identified as mediators of self-renewal, invasiveness, and tumorigenicity by influencing E-cadherin expression, a marker of epithelialmesenchymal transition (EMT) [23]. The phosphorylation of $\mathrm{Cx} 43$, the most ubiquitously expressed connexin, has been implicated in the regulation of GJIC at several stages, e.g., the export of the protein to the plasma membrane, the formation and activity of GJs and connexin degradation [24]. For example, the inactivation of ERK $1 / 2$ and p38 MAP kinases by sulforaphane has been suggested to inhibit $\mathrm{H}_{2} \mathrm{O}_{2}$-induced phosphorylation of $\mathrm{Cx} 43$ and a block of GJIC in rat normal liver cells [25]. In addition, epigenetic mechanisms may be involved in the regulation of $\mathrm{Cx} 43$ protein levels, because previous findings demonstrated that the HDAC inhibitor 4-phenylbutyrate increased the expression of $\mathrm{Cx} 43$ in pancreatic cancer cells and promoted the growth inhibition of xenograft tumors [26]. Similarly, the hypermethylation of the $\mathrm{Cx} 43$ promoter was correlated with low $\mathrm{Cx} 43$ expression in human gliomas and lung cancer [23, 27].

In the present study, we demonstrate that the degree of CSC features and gemcitabine resistance directly correlates with dysfunctional GJIC due to low or absent $\mathrm{Cx} 43$ protein levels. Our results provide new mechanistic insight into stem cell signaling and suggest a dietary strategy consisting of sulforaphane-containing cruciferous vegetables for the restoration of defective GJIC in pancreatic cancer, which could promote re-sensitization to current chemotherapeutics.

\section{RESULTS}

\section{The loss of GJIC correlates with a CSC-like phenotype and gemcitabine resistance.}

To evaluate the relationship between GJIC and therapy resistance, 3 established human PDA cell lines with different levels of therapy sensitivity were treated with 50,100 or $3,000 \mathrm{nM}$ gemcitabine and cell viability was examined using the MTT assay $72 \mathrm{~h}$ after treatment. At the lowest dose, cell viability was reduced from 100 $\%$ to 34,82 and $95 \%$ in sensitive BxPc-3, the derived gemcitabine-resistant subclone $\mathrm{BxPc}-3$-GEM and resistant AsPC-1 cells, respectively, with a comparable response at higher gemcitabine concentrations (Fig. 1A). This result was confirmed by measuring apoptosis with annexin staining and FACS analysis (Fig. 1A). The gemcitabine resistance of the PDA cell lines correlated with the amount of CSC features, such as p53 and K-ras status, morphology, self-renewal potential, tumorigenicity, and the expression of E-cadherin and vimentin (Table S1). In the following experiments, these cells were used as in vitro models for PDA with low (BxPc-3), median (BxPc-3-GEM) and high (AsPC-1) CSC characteristics. We microinjected the membrane-impermeable but GJpermeable fluorescent dye Lucifer Yellow [30] and documented diffusion of fluorescence to neighboring cells by fluorescence microscopy and video recording. For data analysis gray values of fluorescence intensity were evaluated by image processing and the gray value of the directly injected cell was set to $100 \%$ (Fig. 1B, C). The gray values of direct neighboring cells in the first row surrounding the injected cell were 50, 20 and $0 \%$ in BxPc3, BxPc-3-GEM and AsPC-1 cells, respectively. The staining of indirect neighbors located in the second row was detectable in BxPc-3 cells only. This result is 
reflected by the evaluation of the means of gray values of all neighboring cells in each cell line, which was highest in BxPc-3 cells (Fig. 1D). The blockade of GJs with $18 \alpha \mathrm{GA}$ was used as negative control and completely prevented the diffusion of Lucifer Yellow in all cell lines as expected (Fig. 1C, D). These observations were strengthened by co-incubation studies with fluorescencelabeled cells followed by examination of the fluorescence

\section{A}

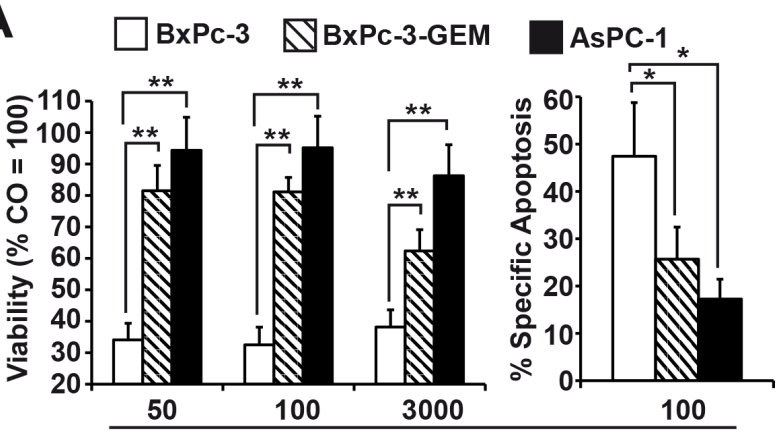

B
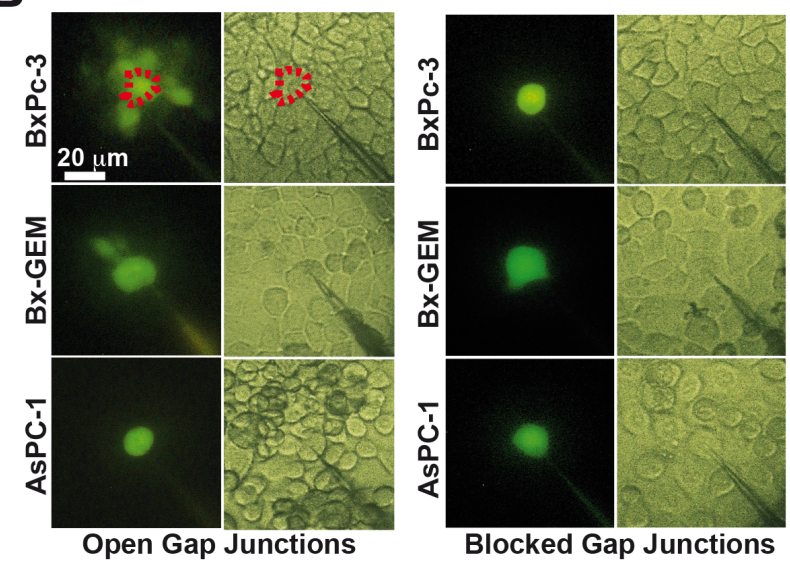

C
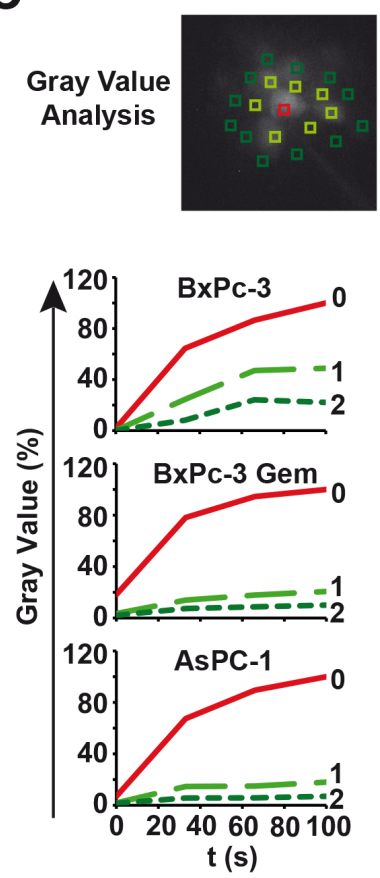

intensity in unlabeled target cells and by co-incubation of gemcitabine-treated and -untreated cells and studying the gemcitabine bystander effect (Fig. S1).

To evaluate whether the reduced expression of a specific connexin is responsible for impaired GJIC, we studied the expression patterns of the standard connexins Cx32, 26, 36, 45 and 43 by Western blot analysis. While Cx26, 32 and 36 levels were enhanced in BxPc-3-GEM and AsPC-1 cells compared to BxPc-3 and non-malignant, immortalized pancreatic ductal CRL-4023 cells, Cx43 and 45 levels were diminished in the more malignant cells, with the strongest effects observed for $\mathrm{Cx} 43$ compared to BxPc-3 and CRL-4023 cells (Fig. 2A). Because the expression of connexins on the cell surface is essential for GJ functionality, we evaluated the cell surface expression by double immunofluorescence stainings for the cell surface marker EpCAM combined with either Cx26, $32,36,43$ or 45 . In line with the Western blot results, fluorescence microscopy revealed strong expression of $\mathrm{Cx} 43$ on the cell surface of BxPc-3 cells; however, this expression was diminished in BxPc-3-GEM and totally absent in AsPC-1 cells (Fig. 2B). The staining patterns of all other connexins were diffuse in all cell lines without obvious cell surface expression (Fig. S2), which argues against a major role in conferring functional GJs. In addition, electron microscopy revealed the presence of functional GJs in BxPc-3 cells, as closely apposed membranes separated by a faint gap were visible (Fig. 2C). In contrast, gap-like structures between neighboring AsPC-1 cells were characterized by constant spacing and gaps filled with contrasting material. These gaps were too wide for regular GJ arrays; therefore, our data suggest that

Figure 1: Loss of GJIC correlates with a CSCphenotype. (A) BxPc-3, BxPc-3-GEM and AsPC-1 human PDA cells were treated with gemcitabine (GEM) at the indicated concentrations. Seventy-two hours later, viability was measured with the MTT assay and apoptosis by annexin staining followed by FACS analysis. Specific apoptosis was calculated using the formula $100 \times[($ experimental apoptosis \%) - spontaneous apoptosis of $\mathrm{CO}(\%)] /[100$ - spontaneous apoptosis of CO $\%$ ]. (B) After microinjection of Lucifer Yellow the diffusion of dye from the injected cell to neighboring cells was detected by fluorescence microscopy and video recording in the presence or absence of the gap junction blocker $18 \alpha \mathrm{GA}(10 \mathrm{mM})$, which was incubated for $30 \mathrm{~min}$ prior to the injection of Lucifer Yellow. Representative images from fluorescence and light microscopy are shown. Representative cells injected with Lucifer Yellow are marked by dotted lines, and the scale bar indicates $20 \mu \mathrm{m}$. (C) Gray values of the injected cell ( 0 , red line), the first raw of neighboring cells (1, light green-dotted line) and the second raw of neighboring cells (2, middle green-dotted line) were determined from the video pictures at the time points $0,20,40$, 60,80 and $100 \mathrm{~s}$ after injection of lucifer yellow and are shown in the diagrams. (D) The means of gray values of all neighboring cells per cell line were calculated and are shown in the diagram \pm SD. $* * p<0.01 ; * p<0.05$. 
non-functional GJs are present in AsPC-1 cells, which is most likely due to the absence of $\mathrm{Cx} 43$ on the cell surface.

In surgically resected human pancreas tissue we found high levels of Cx43 phosphorylated at Ser 368 and at Ser 279/282 in non-malignant pancreas tissue derived from 6 organ donors but not in malignant PDA tissue derived from 6 patients (Fig. 3A, B). These data were confirmed in additional PDA tissues derived from 3 patients, in which total $\mathrm{Cx} 43$ was completely absent in the malignant parts of the sections but present in the non-malignant parts of each individual tissue (Fig. 4A). This correlated to expression of E-cadherin, which was expressed in normal pancreas tissue, but not in malignant pancreas tissue, as examined

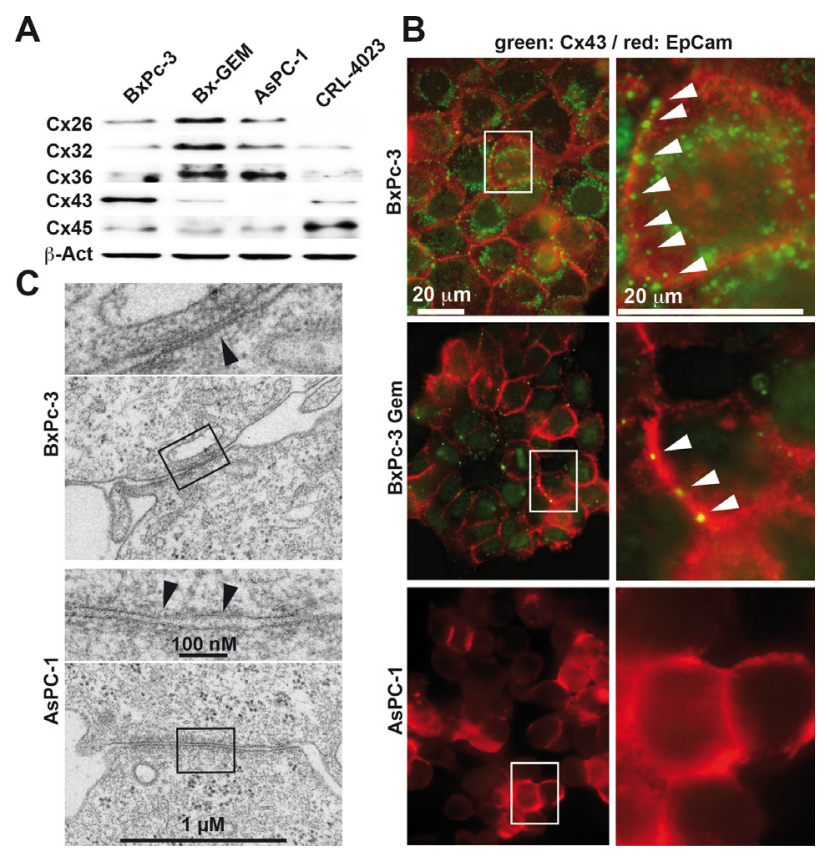

Figure 2: Loss of Cx43 expression in cells with CSC features. (A) Proteins were harvested from PDA cells and immortalized pancreatic ductal cells (CRL-4023), and the expression of Cx26, Cx32, Cx36, Cx43 (anti-Cx43 Ab was from Invitrogen) and $\mathrm{Cx} 45$ was analyzed by Western blot. The expression of $\beta$-Actin ( $\beta$-Act) served as a loading control. (B) The expression and cellular localization of $\mathrm{Cx} 43$ (Cell Signaling) was analyzed by double immunofluorescence staining using antibodies specific for $\mathrm{Cx} 43$. Co-staining with the cell surface protein EpCAM was performed to mark the cell surface. Cx43positive cells were visualized with Alexa Fluor 488 (green), and EpCAM-positive cells were visualized with Alexa Fluor 594 (red). The arrows mark $\mathrm{Cx} 43$ expression on the cell surface. Cells were analyzed under $400 \times$ magnification using a Leica DMRB fluorescence microscope. Images of representative fields were captured using a Kappa CF 20/4 DX digital color camera (Kappa GmbH, Gleichen, Germany) and Kappa ImageBase 2.2 software. All photographs were taken at the same magnification, and the scale bar indicates $20 \mu \mathrm{m}$. (C) Electron microscopy of gap junction-like cell-cell contacts of BxPc-3 and AsPC-1 cells. The arrows indicate the extension of junctions with a narrow gap in $\mathrm{BxPc}-3$ cells, and the inserts show details of the gaps at higher magnification. The scale bar indicates $1 \mu \mathrm{m}$. by double immunofluorescence staining of total $\mathrm{Cx} 43$ and E-Cadherin followed by fluorescence microscopy (Fig. 4B).

\section{The inhibition of Cx43 prevents GJIC and promotes tumor aggressiveness.}

To further elucidate the function of $\mathrm{Cx} 43$ for GJIC and CSC features in pancreatic cancer, we knocked down Cx43 in low-malignant BxPc-3 cells by $\mathrm{Cx} 43$-directed siRNAs. Compared to the non-specific control siRNA, 2 of 5 tested specific siRNAs completely downregulated Cx43 protein expression at a concentration of $50 \mathrm{pmol}$, and the strongest effects were observed 3 days after transfection, as evaluated by Western blot analysis (Fig. 5A, Fig. S3). For subsequent experiments, siRNA-transfected BxPc-3 cells were microinjected with Lucifer Yellow, followed by video analysis of dye diffusion and analysis of gray values. Compared to cells transfected with control siRNA, the specific siRNA targeting Cx43 decreased the average staining of the neighboring cells in the first cell row from 50 to $30 \%$ and in the second row from 20 to $15 \%$ (Fig. 5B). In parallel, the viability of $\mathrm{Cx} 43$ siRNA-transfected BxPc-3 cells increased and the gemcitabine bystander effect was completely abolished, as measured by the coincubation of gemcitabine-treated and non-treated cells (Fig. 5C). Furthermore, the downregulation of $\mathrm{Cx} 43$ enhanced the colony-forming capacity (Fig. 5D) and led to the induction of stem cell-associated factors including Oct-3/4, Nanog, SOX2 and TP65 as well as the EMTrelated transcription factor Snail, as measured using an antibody protein array (Fig. 5E).

\section{Sulforaphane enhances $\mathrm{Cx} 43$ protein levels and GJIC and changes Cx43 phosphorylation patterns.}

In an attempt to enhance $\mathrm{Cx} 43$ expression to restore GJIC and to inhibit CSC features, we performed treatments with sulforaphane, and examined the expression of Cx43 by Western blot analysis. Compared to untreated control cells, sulforaphane strongly increased the amount of total $\mathrm{Cx} 43$ in all cell lines examined (Fig. 6A). Basal Cx43 phosphorylated at Ser 368 was highest in BxPc-3 cells. Sulforaphane led to a time-dependent increase of the low basal levels of $\mathrm{Cx} 43$ phosphorylated at Ser 368 already $2 \mathrm{~h}$ after treatment in BxPc-3-GEM and AsPC-1 cells, whereas the high basal expression in BxPc3 cells was not further increased, but rater decreased. Moreover, the expression of $\mathrm{Cx} 43$ phosphorylated at Ser $279 / 282$ was increased by sulforaphane treatment in all 3 cell lines. Sulforaphane also induced the expression of E-cadherin in all 3 cell lines, but stronger expression was observed in the 2 more aggressive cell lines demonstrating lower basal levels. To evaluate whether sulforaphane- 
A Normal Pancreas $\quad$ p-Cx43 (S 368) Pancreatic Ductal Adenocarcinoma

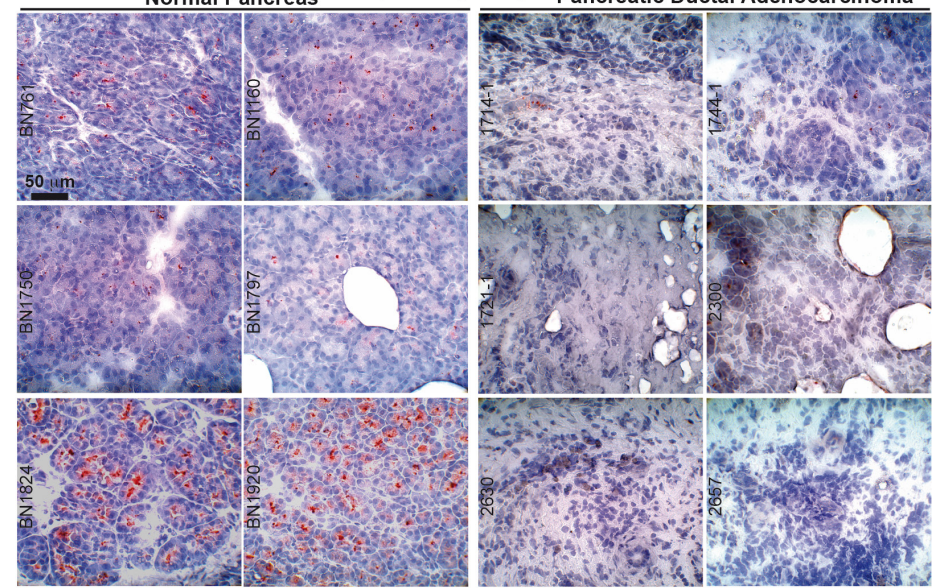

B

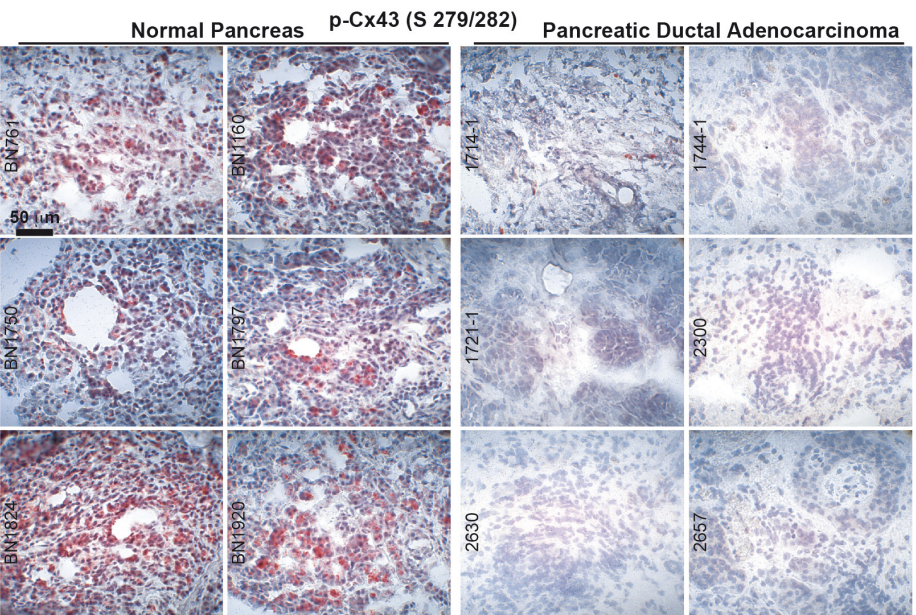

Figure 3: Cx43 is downregulated in malignant pancreas tissue but not in normal pancreas tissue. (A) The expression of Cx43 phosphorylated at Ser 368 (Ab from Abcam) was analyzed by immunohistochemistry in frozen 6- $\mu$ m-thick tissue sections of nonmalignant human pancreatic tissue derived from 6 organ donors. Labeled anti-rabbit polymer-HRP was used as the secondary antibody. (B) Likewise, the expression of $\mathrm{Cx} 43$ phosphorylated at Ser 279/282 was analyzed in the same tissues and by the same technique.

Pancreatic Ductal Adenocarcinoma
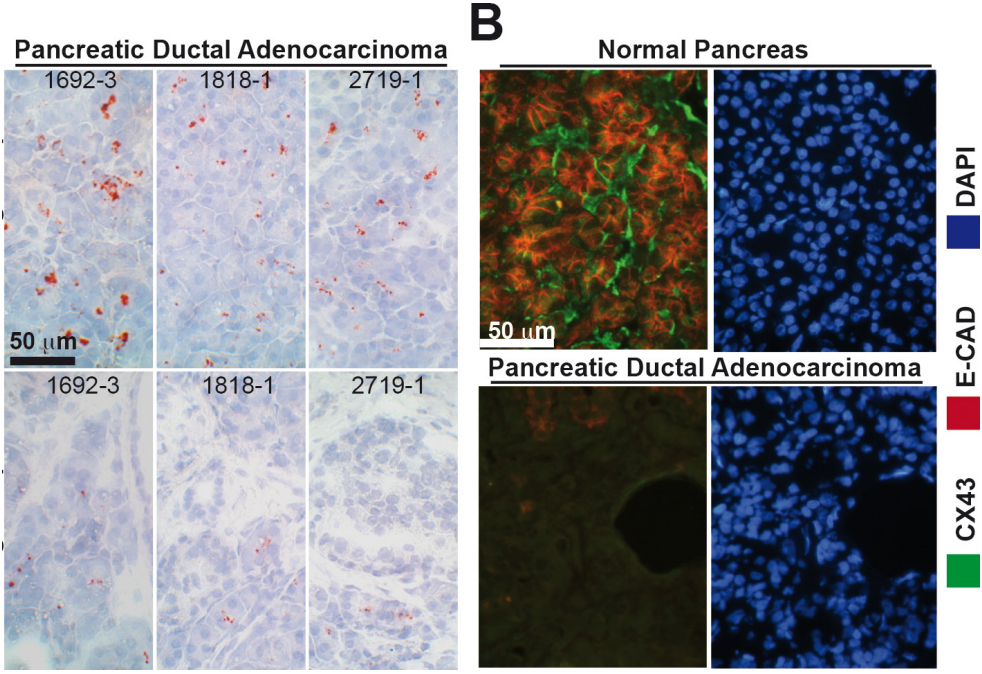

Figure 4: $\mathrm{Cx} 43$ and E-Cadherin are downregulated in malignant but not in non-malignant parts of pancreas tissue from the same patients. (A) The expression of total $\mathrm{Cx} 43$ (Invitrogen) was analyzed in the malignant and non-malignant parts of frozen 6- $\mu \mathrm{m}$-thick tissue sections of pancreas tissue derived from 3 patients. (B) The expression of total $\mathrm{Cx} 43$ (Invitrogen) and E-cadherin (E-CAD) was analyzed by double immunofluorescence staining of malignant and non-malignant parts of a patient-derived PDA tissue section. Cx43-positive cells were visualized with Alexa Fluor 488 (green), and E-cadherin-positive cells were visualized with Alexa Fluor 594 (red). DAPI staining indicates the cell nuclei. Tissue sections were analyzed under $400 \times$ magnification. The scale bars indicate $50 \mu \mathrm{m}$. 
mediated induction of $\mathrm{Cx} 43$ expression was accompanied by enhanced GJIC, we microinjected Lucifer Yellow into untreated or sulforaphane-treated BxPc-3-GEM cells. Video analysis of dye diffusion and the analysis of gray values revealed that sulforaphane increased GJIC (Fig. 6B). The results of electron microscopy correlated with these findings, as the contrasting material in gaplike structures between neighboring AsPC-1 cells was diminished after sulforaphane treatment (Fig. 6C) compared to untreated AsPC-1 cells (Fig. 2C). Finally, inhibition of GSK3, PKC and JNK by the inhibitors BIO, staurosporine and SP600125, respectively, diminished the sulforaphane-induced expression of total $\mathrm{Cx} 43$ and of Cx43 phosphorylated at Ser 368 as shown in AsPC-1 cells (Fig. 6D). This result, together with the finding that sulforaphane influences the phosphorylation of numerous kinases and their substrates in a time-dependent manner

A

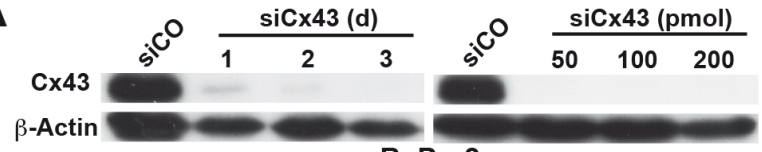

BxPc-3

B

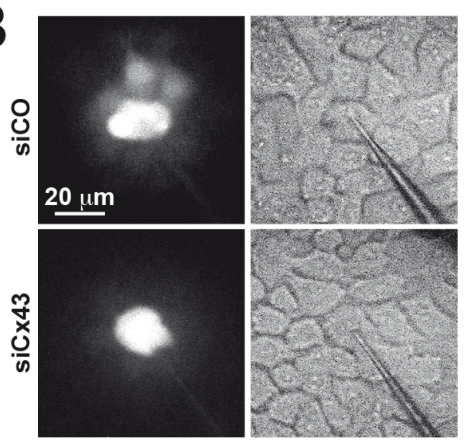

C

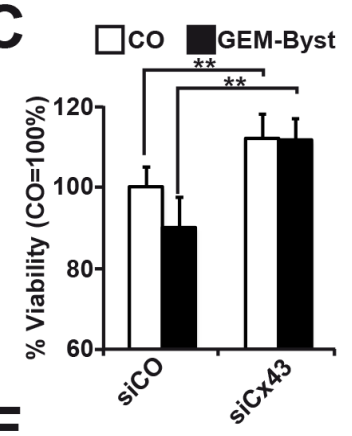

E

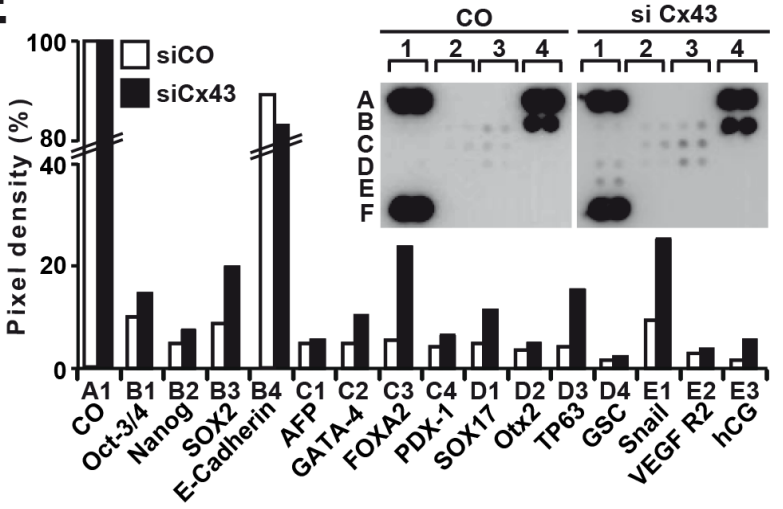

(Fig. S4) suggests that postranslation phosphorylation is involved in enhanced expression of $\mathrm{Cx} 43$. In contrast, sulforaphane did not upregulate $\mathrm{Cx} 43$ mRNA expression, as measured by qRT-PCR (Fig. S5); did not increase the demethylation of the $\mathrm{Cx} 43$ promoter, as measured by quantitative methylation analysis of the GJA1 (Cx43) gene (Fig. S6); and did not enhance the binding of acetylated histones to the GJA1 promoter as measured by chromatin immunoprecipitation of acetylated histones 3 and 4 followed by the analysis of several regions surrounding the GJA1 transcription start site by qPCR (Fig. S7). Remarkably, enhanced methylation of the $\mathrm{Cx} 43$ promoter in untreated AsPC-1 cells compared to BxPc3 and BxPc-3-GEM cells was detected (Fig. S6), which may be responsible for the non-detectable expression of Cx43 mRNA in AsPC-1 cells (Fig. S5). Therefore, elevated $\mathrm{C} \times 43$ protein levels after sulforaphane were most likely due to the altered phosphorylation and stabilization

Figure 5: Silencing of Cx43 blocks GJIC and induces therapy resistance and clonogenicity. (A) BxPc-3 cells were treated with non-specific siRNAs (siCO) or specific siRNAs directed against $\mathrm{Cx} 43$ ( $\mathrm{siCx} 43$ ) for 3 days. The protein expression of $\mathrm{Cx} 43$ was analyzed by Western blot on days 1,2 and 3 after incubation with siRNA or $3 \mathrm{~d}$ after incubation with siRNA at concentrations of 50, 100 or 200 pmol, as described in Fig. 3A. (B) BxPc-3 cells were treated with 50 pmol siRNA for $72 \mathrm{~h}$ followed by microinjection of Lucifer Yellow, and the monitoring of dye diffusion was performed as described in Fig. 1C. Pictures were extracted from the videos at distinct time points, and the gray values were calculated. The average gray value of the first neighbors (1) and second neighbors (2) and the gray value of the injected cell (0) are shown as the percentage over a period of $100 \mathrm{~s}$. The data shown represent the means of 3 independent experiments. (C) The cells were treated with 50 pmol siRNA against $\mathrm{Cx} 43$ ( $\mathrm{siCx} 43)$ or non-specific control siRNA (siCO) for $72 \mathrm{~h}$. Then, the cells were left untreated or were treated with gemcitabine for $24 \mathrm{~h}$, followed by co-culture at a ratio of 1:1 for $24 \mathrm{~h}$. The viability of untreated cells $(\mathrm{CO}$, white bars) and of cells co-cultured with gemcitabine-treated cells (GEM-Byst, black bars) was measured using the MTT assay. (D) Three days after transfection with siCO or siCx43, $1 \times 10^{3} \mathrm{BxPc}-3$-GEM cells/well were seeded onto 6 -well plates. The cells were grown without a change of the medium for 2 weeks, followed by the evaluation of fixed and Coomassiestained colonies containing at least 50 cells. The percentage of plating efficiency was calculated with the formula $100 \times$ number of colonies/number of seeded cells. The data shown represent the means \pm SD $(* * p<0.01)$. (E) Proteins were isolated $3 \mathrm{~d}$ after transfection of BxPc-3 cells with siCO or siCx43, and the binding of proteins to antibodies spotted in duplicate to the membrane of a Human Pluripotent Stem Cell Array was detected using biotinylated secondary antibodies, streptavidin-HRP and chemiluminescence. The pixel density was quantified using Image J software and normalized to the mean pixel intensity of reference spots located at the coordinates A1, A4 and F1 on the membrane. Spot E4 is the negative control, where PBS instead of the antibody was spotted onto the membrane. The mean values from duplicate experiments with a similar outcome are shown. 
of $\mathrm{Cx} 43$ protein; although the phosphorylation pattern of Cx43 varied between cell lines, which is in line with a recent report [31].

To further highlight these findings in primary CSC-marker-positive cells, we selected primary CSCs by transplantation of freshly resected PDA tissue from two patients to immunodeficient mice. For enrichment of CSCs we subtransplanted the xenografts for several rounds. During subtransplantation, the tumor morphology and tumor stroma were largely preserved, as ensured by Trichrome staining of the primary tumors and its xenografts (Fig. 7A and data not shown), whereas the latency and the tumor take rate increased (data not shown). Accordingly, the CSC marker c-Met was enriched from $17 \%$ in the primary tumor to $32 \%$ in xenografts at passage 3. The expression of Cx43 phosphorylated at Ser 368 was also detected in the primary tumor tissue and its xenografts; however, quantitative evaluation was not possible due to the expression of $\mathrm{Cx} 43$ between neighboring cells. To examine the effect of sulforaphane on CSC features, we further enriched CSC-marker positive cells from passage 7 xenografts of the 2 patient tumors by isolation of tumor cells and in vitro spheroidal culture (Fig. 7B). This culture technique favored the growth of $\mathrm{CSCs}$, because the ability to grow anchorage-independent is considered as a property of CSCs, and this is reflected by the enhanced expression of the CSC markers c-Met $(\sim 75 \%)$ and CD133 $(\sim 80 \%)$, as detected by the preparation of cytospins and immunohistochemistry (Fig. 7C). Moreover, the treatment of the spheroidal cultures with sulforaphane for $24 \mathrm{~h}$ increased the expression level of $\mathrm{Cx} 43$ phosphorylated at Ser 368, E-cadherin and active caspase 3, whereas the levels of c-Met and CD133 decreased. These results demonstrate that $\mathrm{Cx} 43$ expression is low in primary CSCs, but can be increased by sulforaphane treatment, which is associated with inhibition of CSC and EMT markers and induction of apoptosis.

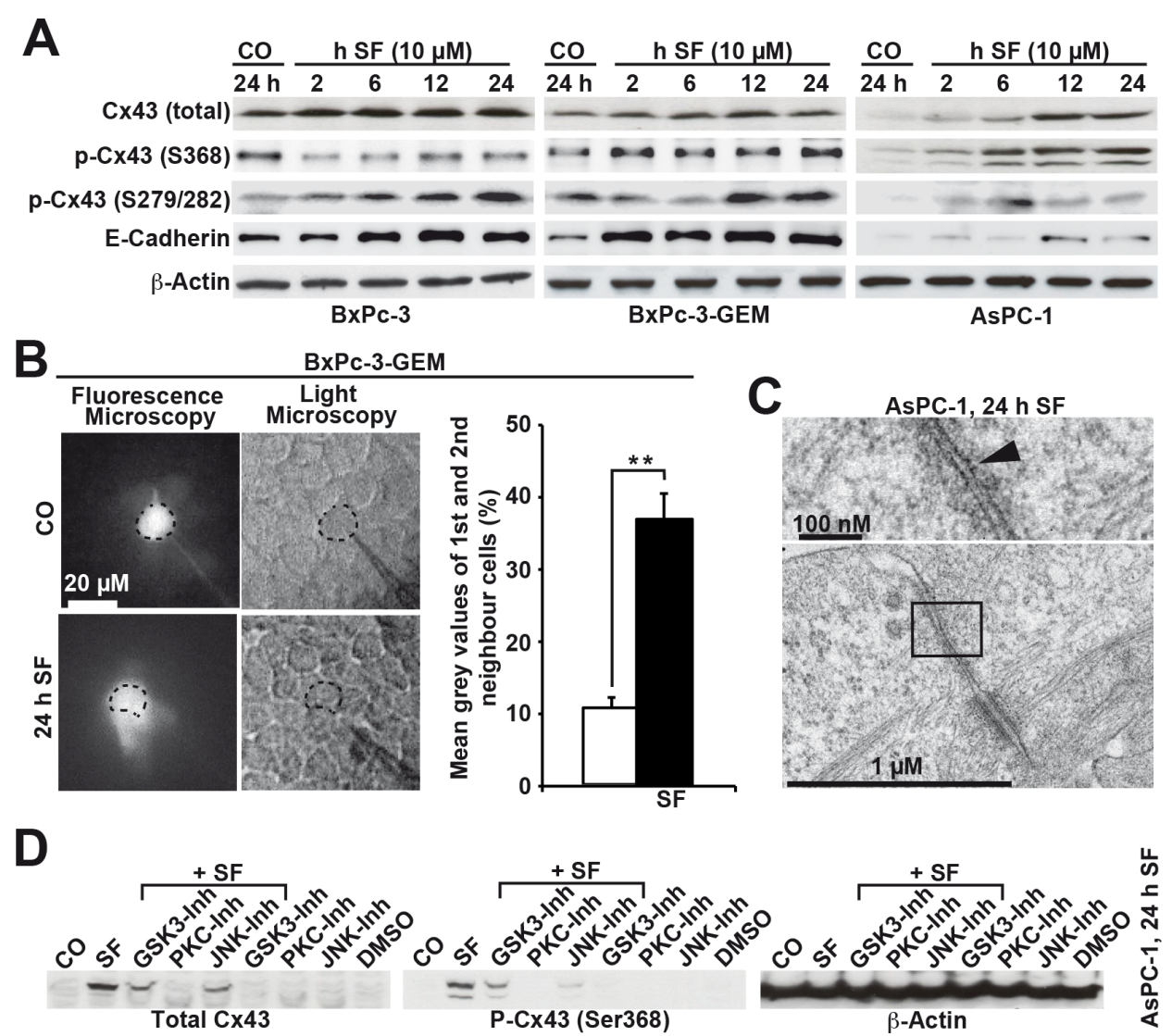

Figure 6: Sulforaphane enhances GJIC and $\mathrm{Cx43}$ protein expression, which is prevented by inhibition of kinase activity. (A) BxPc-3, BxPc-3-GEM and AsPC-1 cells were left untreated or were treated with sulforaphane (SF, $10 \mu \mathrm{M})$ and time points indicated. The proteins of all treatment groups were harvested at the same time point, and Western blot analysis was performed using antibodies to detect total $\mathrm{Cx} 43$ with an antibody, which does not detect Cx43 phosphorylated at Ser 368 (Invitrogen), Cx43 phosphorylated at Ser 368 (Abcam), Cx43 phosphorylated at Ser 279/282, E-cadherin and $\beta$-Actin. (B) BxPc-3 cells were treated with sulforaphane (SF, 10 $\mu \mathrm{M})$ or were left untreated (CO). Twenty-four hours later, the cells were analyzed as described in Fig. 5B. The mean gray values of the $1^{\text {st }}$ and $2^{\text {nd }}$ neighbors of all time points are shown. (C) Electron microscopy of AsPC-1 cells, which were left either untreated or were treated with sulforaphane (SF, $10 \mu \mathrm{M})$ for $24 \mathrm{~h}$, was performed as described in Fig. C. (D) AsPC-1 cells were left untreated or were treated with sulforaphane (SF, $10 \mu \mathrm{M})$ in the presence or absence of the GSK3-inhibitor BIO $(10 \mu \mathrm{M})$, the PKC-inhibitor staurosporine (100 nM) or the JNK-inhibitor SP600125 $(10 \mu \mathrm{M})$. Treatment with the inhibitors alone or with the solvent DMSO served as control. Proteins were harvested $24 \mathrm{~h}$ after treatment and the expression of total $\mathrm{Cx} 43, \mathrm{Cx} 43$ phosphorylated at Ser 368 and $\beta$-Actin was examined by Western blot analysis. 


\section{DISCUSSION}

We examined GJIC in human pancreatic cells and
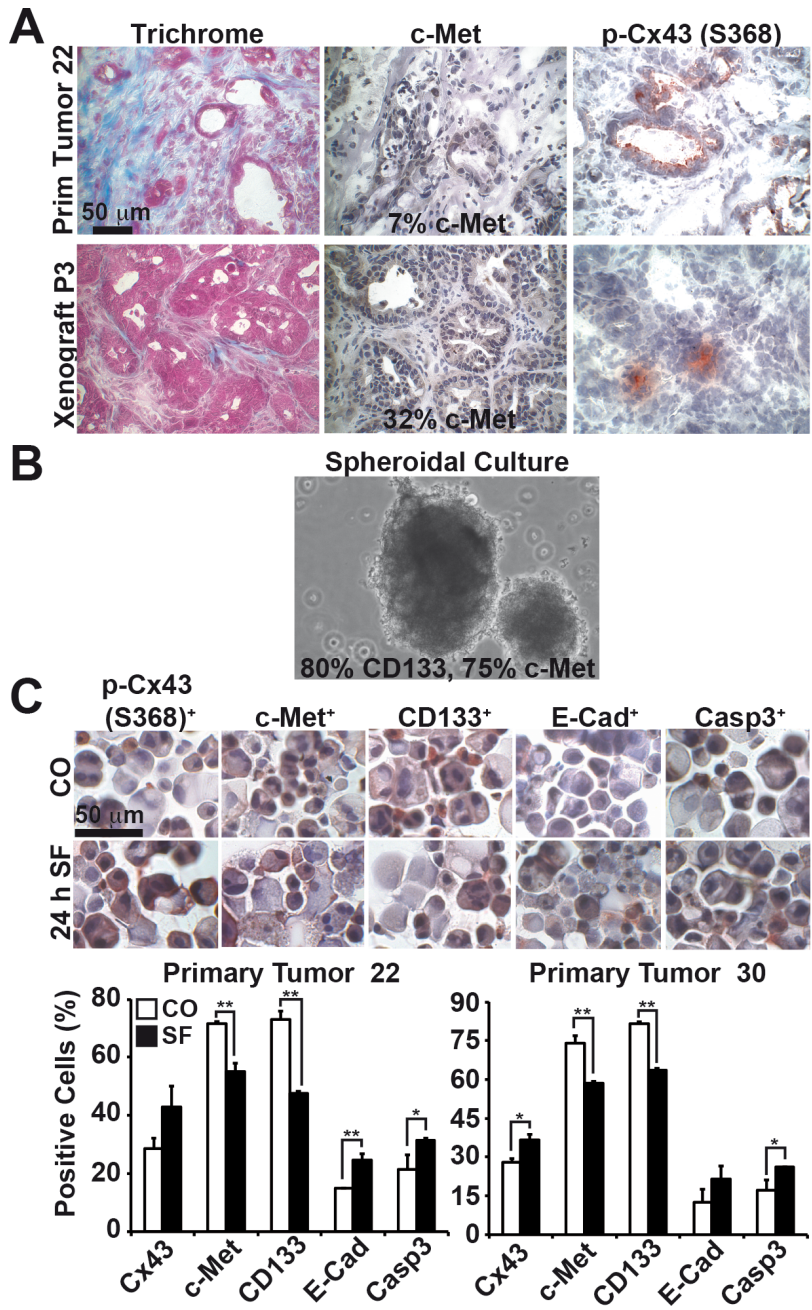

Figure 7: Sulforaphane induces Cx43 and inhibits CSC characteristics in primary CSCs. (A) Staining of patientderived frozen tissue from a ductal adenocarcinoma (Primary Tumor 22) and it's derived xenograft from passage 3 (Xenograft P3) with Trichrome, c-Met or Cx43 phosphorylated at Ser 368 (Abcam), followed by microscopical evaluation under $400 \times$ magnification. The scale bar indicates $50 \mu \mathrm{m}$. (B) Representative picture of an anchorage-independent growing spheroidal culture established from a mouse xenograft derived from the primary patient tumor 22. The percentage of expression of the CSC markers c-Met and CD133 was determined as described in part $\mathrm{C}$ and is indicated. (C) One week after in vitro spheroidal culture, cells derived from pancreatic ductal adenocarcinoma 22 and 30 were left untreated or were treated with sulforaphane $(10 \mu \mathrm{M})$. Twenty-four hours later, the cells were cytospinned to glass slides, and the expression of $\mathrm{Cx} 43$ phosphorylated at Ser 368 (Abcam), c-Met, CD133, E-cadherin and the cleaved, active fragment of Caspase- 3 was examined by immunohistochemistry. The number of positive cells was quantified in 10 vision fields under $400 \times$ magnification and the means \pm SD are shown in the diagrams. ${ }^{* *} \mathrm{p}<0.01,{ }^{*} \mathrm{p}<0.05$. tissues and found a direct correlation among low $\mathrm{Cx} 43$ protein levels, blocked GJIC, gemcitabine resistance, CSC features and EMT marker expression. In particular, less malignant and GJIC-competent BxPc-3 cells expressed $\mathrm{Cx} 43$ protein at a high level on the cell surface and showed morphologically intact GJs; however, $\mathrm{Cx} 43$ was not expressed in highly malignant AsPC-1 cells with blocked GJIC and morphologically non-functional GJs. BxPc-3-GEM cells were intermediate malignant subclones of $\mathrm{BxPc}-3$ cells and exhibited weaker expression of $\mathrm{Cx} 43$, which was primarily localized to the cytoplasm rather than to the cell surface. These findings suggest that cytoplasmic localization of $\mathrm{Cx} 43$ induces the dysregulation of GJs by $\mathrm{Cx} 43$ withdrawal from the cell membrane during early tumor progression (BxPc3-GEM), which may be followed by complete silencing of $\mathrm{Cx} 43$ expression in later tumor stages (AsPC-1). In this regard, changes in $\mathrm{Cx} 43$ expression and localization during pancreatic cancer progression have been recently described in the murine system and suggest a potential role for GJs and $\mathrm{Cx} 43$ in mediating interactions between and amongst the stromal and epithelial cells [32]. Another suggested mechanism for $\mathrm{Cx} 43$ translocation from the cell surface, along with the reduction of GJIC, involves the hypophosphorylation of $\mathrm{Cx} 43$, as demonstrated in oncogene-transformed rat liver epithelial cells and the occurrence of phosphorylated $\left(\mathrm{P}_{1}, \mathrm{P}_{2} \mathrm{P}_{2}^{\prime} \mathrm{P}_{3}\right)$ and unphosphorylated $\mathrm{P}_{0} \mathrm{Cx} 43$ immunoreactive bands in Western blot analysis [33]. This hypothesis corresponds to our stainings of human pancreatic cancer tissues, in which the high expression of $\mathrm{Cx} 43$ phosphorylated at Ser 368 and Ser 279/282 was detected in non-malignant tissue only. The key phosphorylation events at different $\mathrm{Cx} 43$ serine residues responsible for regulating the GJ life cycle are complex and differentially regulated between different cell types and amino acid residues, and were therefore not examined in detailed in the present report. However, the underlying signaling pathways of $\mathrm{Cx} 43$ phosphorylation appear to involve MAPK activity [31]. In this regard, the activity of JNK, ERK and p38 MAP kinases and the subsequent enhanced phosphorylation of $\mathrm{Cx} 43$ have been shown to inhibit $\mathrm{Cx} 43$ protein expression [25, 34]. In our studies, the sulforaphane-mediated elevated levels of $\mathrm{Cx} 43$ were prevented by inhibitors of GSK3, JNK and $\mathrm{PKC}$, which suggests the involvement of these kinases in phosphorylation of $\mathrm{Cx} 43$, which may lead to enhanced protein levels. This suggestion is underlined by our finding that sulforaphane influenced the phosphorylation patterns of several kinases and their substrates in a time-dependent manner.

To demonstrate the strong impact of $\mathrm{Cx} 43$ on GJIC in pancreatic cancer, we inhibited $\mathrm{Cx} 43$ expression by siRNA transfection in GJIC-competent BxPc-3 cells, leading 
to a completely abrogated GJIC, which was associated with a higher basal viability, resistance to gemcitabine, enhanced clonogenic potential and the induction of stem cell-associated factors. This finding is supported by observations made by $\mathrm{Yu}$ and colleagues [23], who identified the expression of $\mathrm{Cx} 43$ in more differentiated and GJIC-competent human glioma cells, while glioma stem cells were GJIC-incompetent and $\mathrm{Cx} 43$ negative. Hence, adenoviral reconstitution of $\mathrm{Cx} 43$ expression in glioma stem cells inhibited their capacity for selfrenewal, invasiveness and tumorigenicity by influencing E-cadherin expression [23]. As an underlying mechanism for reduced Cx43 expression in glioma stem cells, these previous authors suggested that hypermethylation of the promoter of the GJ protein $\alpha 1$, which encodes $\mathrm{Cx} 43$ [23], may regulate this process. This hypothesis was evaluated by measuring the immunoprecipitation of methylated DNA (MeDIP) followed by PCR amplification of 2 potentially methylated regions in the GJA1 (Cx43) promoter. We confirmed this result in our system and used quantitative EpiTYPER methylation profiling of the region surrounding the $C x 43$ transcription start site. We also detected enhanced $C x 43$ promoter methylation in CSC-like AsPC-1 cells compared to the less malignant BxPc-3 and BxPc-3-GEM cells. Thus, strongly enhanced promoter methylation of $\mathrm{Cx} 43$ may be responsible for the observed absent RNA and protein expression of Cx43 in AsPC-1 cells. However, it remains unclear how dysfunctional GJIC supports a CSC phenotype and tumor progression. A reasonable explanation is that dysfunctional GJIC prevents influences from surrounding normal tissue cells [35], thereby enabling CSCs to escape growth control mechanisms and apoptosis induction $[20,36]$.

We demonstrated that sulforaphane stimulated the elevated expression of defective $\mathrm{Cx} 43$ in established and primary models of pancreatic CSCs along with the restoration of defective GJIC, the activation of E-cadherin protein and the inhibition of the CSC markers CD133 and c-Met. A main underlying mechanism for these observations may be postranscriptional phosphorylation, because inhibition of GSK3, JNK and PCS inhibited the sulforaphane-induced expression of $\mathrm{Cx} 43$ and sulforaphane influenced the phosphorylation of several kinases and their substrates. We did not observe an effect of sulforaphane on Cx43 RNA expression, promoter methylation or promoter binding of acetylated histones; therefore, the epigenetic regulation of $\mathrm{Cx} 43$ expression by sulforaphane may be excluded. However, our data do not exclude the possibility that sulforaphane generally affects epigenetic regulation, as demonstrated by our Western blot experiments showing enhanced acetylation of histones 3 and 4 after sulforaphane treatment of PDA cells. In addition, work by others has demonstrated the inhibition of DNA methyltransferase and histone deacetylase by sulforaphane $[37,38]$. Our results also do not exclude the involvement of histone acetylation in the basal regulation of $\mathrm{Cx} 43$ expression in pancreatic cancer, which has been suggested by a recent study showing that the HDAC inhibitor 4-phenylbutyrate increases $\mathrm{Cx} 43$ expression and suppresses the growth of human pancreatic cancer cells [26].

The present data demonstrate that reduced $\mathrm{Cx} 43$ protein levels are major mediators of blocked GJIC, which confer a CSC-like phenotype in PDA. However, dietary sulforaphane enhances $\mathrm{Cx} 43$ protein levels, restores GJIC and inhibits CSC features; therefore, a diet rich in cruciferous vegetables containing sulforaphane and related mustard oils may be considered as a supportive nutritional strategy to enhance therapeutic efficacy in patients suffering from pancreatic cancer.

\section{MATERIALS AND METHODS}

\section{Established Cell Lines.}

Established human BxPc-3 and AsPC-1 PDA cell lines and immortalized CRL-4023 hTERT-HPNE human PDA cells were obtained from ATCC. BxPc-3-GEM subclones were selected from parental BxPc-3 cells by continuous culturing in increasing concentrations of gemcitabine up to $100 \mathrm{nM}$ for several months. Cells were cultured in DMEM (PAA, Pasching; Austria) supplemented with 10\% heat-inactivated FCS (SigmaAldrich, Steinheim; Germany) and $25 \mathrm{mmol} / \mathrm{L}$ HEPES (PAA, Pasching; Austria). Cells were authenticated by a commercial service (Multiplexion, Heidelberg, Germany). Monthly tests ensured a mycoplasma-free cell culture.

\section{Reagents.}

A $126 \mathrm{mM}$ gemcitabine solution (Eli Lilly, Indianapolis, IN, USA) used for patients was diluted in cell culture medium to a $100 \mu \mathrm{M}$ stock solution. The gap junction inhibitor 18 $\alpha$-glycyrrhetinic acid (18GA; Sigma-Aldrich, St. Louis, MO; USA) [39] was diluted in DMSO to a $70 \mathrm{mM}$ stock. D,L-sulforaphane $(>90 \%$ pure, Sigma-Aldrich, Steinheim; Germany) was dissolved to create a $50 \mathrm{mM}$ stock solution in EtOH. 5-Aza-2'deoxycytidine ( $>97 \%$ pure, Sigma) was dissolved in acetic acid:water $(1: 1)$ to create a $50 \mathrm{ng} / \mathrm{ml}$ stock solution. The GSK-3 inhibitor BIO and the JNK-inhibitor SP600125 (Selleckchem.com, München, Germany) were dissolved in DMSO to $10 \mathrm{mM}$ stocks and the PKC-inhibitor staurosporine (Selleckchem.com) was dissolved in DMSO to a $1 \mathrm{mM}$ stock. The final concentrations of the solvents in medium were $0.1 \%$ or less. 


\section{Primary Antibodies.}

Rabbit polyclonal antibodies (pAbs) were used against Cx32, Cx26 (Invitrogen, Camarillo, California; USA), c-Met, total $\mathrm{Cx} 43$ (\#3512, Cell Signaling Technology, Boston, MA, USA), Cx43 phosphorylated at Ser 368 (\#ab47368; Abcam, Cambridge, UK), Cx45 phosphorylated at Ser 279/282 (Santa Cruz Biotechnology, Inc. Heidelberg, Germany), Cx45, CD44 (GeneTex, Irvine, California, USA), acetyl-Histone H3 and acetylHistone H4 (Merck Millipore, Darmstadt, Germany), E-cadherin (Cell Signaling), Ki67 (Thermo Scientific, Rockford, IL, USA) and the cleaved fragment of activated human caspase-3 (R\&D Systems, Abingdon, UK). Mouse monoclonal antibodies (mAbs) were used against Cx36, total $\mathrm{Cx} 43$ (which does not detect $\mathrm{Cx} 43$ phosphorylated at Ser 368, \#138300; Invitrogen, Camarillo, California; USA), CD133 (Abcam), $\beta$-Actin (Sigma, St. Louis, MO, USA), EpCAM and the epithelial glycoprotein Egp34 (kindly provided by G. Moldenhauer and described [40]). Another rabbit monoclonal antibody $(\mathrm{mAb})$ was used to detect Cx43 phosphorylated at Ser 368 (\#GTX48551 (Gene Tex (Irvine, California, USA).

\section{Primary Spheroidal Cells.}

Surgical non-diagnostic specimens were mechanically minced, and $2 \times 10^{7}$ cells placed in Matrigel were transplanted to the flanks of 6-week-old NMRI $(\mathrm{nu} / \mathrm{nu})$ female mice. The tumor take rate was $60 \%$, and after the development of a tumor, the xenografts were resected, minced and subtransplanted to new mice. Subtransplantation was repeated until stably growing xenograft lines after passage 3 were obtained. Pancreatic cancer spheres were generated from 2 established xenograft lines, as recently described [4, 41], and the primary spheroidal cultures were used for experiments between days 7 and 30 of culture. Patient material was obtained under the approval of the ethical committee of the University of Heidelberg after written informed consent was obtained from patients. Diagnoses were established by conventional clinical and histological criteria according to the World Health Organization (WHO). All surgical resections were indicated according to the principles and practice of oncological therapy. Animal experiments were also approved by the ethical committee.

\section{Microinjection of Lucifer Yellow.}

The tip of an ultrathin self-made glass pipette was positioned in the intracellular space of a single cell in a subconfluent cell layer in $35-\mathrm{mm}$ dishes. The position was controlled by measuring the membrane potential via the wire in the pipette and the ground electrode in the culture medium. Lucifer Yellow dye (Sigma Aldrich, Germany) was injected with a customized iontophoresis device for $90 \mathrm{~s}$ at a constant current of $10 \mathrm{nA}$. The distribution of Lucifer Yellow was examined by fluorescence microscopy (Zeiss, Oberkochen; Germany) in combination with a CCD Kappa CF 15 DRE camera (Kappa GmbH, Gleichen, Germany) and a video recorder, as recently described [42]. Pictures were extracted from the videos between the onset $(t=0 s)$ and the end of the injection $(t=100$ $\mathrm{s})$. The fluorescence signal was analyzed at $100 \mathrm{~s}$ by calculating the gray values of the directly injected cell and the $1^{\text {st }}$ and $2^{\text {nd }}$ cellular neighbors using customized image data processing software (Histo 3.0, University Hospital Heidelberg, Germany). The gray value of the directly injected cells was set to $100 \%$, and the gray value of the $10^{\text {th }}$ neighboring cell was set to $0 \%$. To block GJIC, the cells were treated with $10 \mu \mathrm{M} 18 \alpha$-glycyrrhetinic acid (18aGA; Sigma-Aldrich, St. Louis, MO; USA) $30 \mathrm{~min}$ prior to microinjection.

\section{Electron Microscopy.}

Cells were processed for electron microscopy according to standard procedures. Briefly, the 3-step fixation process included $1 \mathrm{~h}$ on ice in $2.5 \%$ glutaraldehyde (EM-grade, Sigma) buffered to $\mathrm{pH} 7.2$ with $40 \mathrm{mM} \mathrm{Na}$ cacodylate, $2.4 \mathrm{mM} \mathrm{MgCl}, 50 \mathrm{mM} \mathrm{KCl}$ and $58 \mathrm{mM}$ sucrose, followed by $1 \mathrm{~h}$ on ice in $1 \%$ aqueous $\mathrm{OsO}_{4}$ and overnight at $4^{\circ} \mathrm{C}$ in $0.5 \%$ aqueous uranyl acetate. After dehydration in graded steps of ethanol, the adherent cells were flat-embedded in epoxy resin (Polysciences, Eppelheim, Germany). Ultrathin sections parallel to the substrate-plane were prepared at a $40-\mathrm{nm}$ nominal thickness, post-stained in Reynold's lead citrate and $4 \%$ aqueous uranyl acetate and viewed with an EM900 transmission electron microscope (Zeiss, Oberkochen, Germany) at $80 \mathrm{kV}$. Images were captured on image plates at $16,000 \times$ primary magnification and were scanned with a 15- $\mu \mathrm{m}$ step-size (Ditabis Micron, Pforzheim, Germany).

\section{Antibody Protein Array.}

Nitrocellulose membranes, on which capture antibodies were spotted, and reagents for detection were obtained as a kit (Human pluripotent stem cell antibody array, Human phospho-kinase array) from R\&D Systems ${ }^{\circledR}$ (Wiesbaden, Germany). According to the manufacturer's instructions, protein extracts were prepared and then incubated with the nitrocellulose membranes, and specific protein binding was detected with biotinylated secondary antibodies using streptavidin-HRP and chemiluminescence detection reagents. 


\section{Protein Isolation and Western Blot Analysis.}

Whole-cell extracts were prepared using a standard protocol, and proteins were detected by Western blot analysis using specific primary antibodies as described above. Goat anti-rabbit or goat anti-mouse secondary antibodies conjugated to horseradish peroxidase (HRP) (Santa Cruz, CA; USA) and Luminata Forte Western HRP Substrate (Millipore Corporation, Billerica, MA; USA) were used for detection.

\section{MTT Assay.}

Cells were seeded in 96-well plates at $4 \times 10^{3}$ cells/ well and treated with gemcitabine $24 \mathrm{~h}$ later. After an additional $72 \mathrm{~h}$, viability was determined using the 3-(4,5-dimethylthiazol-2-yl)-2,5-diphenyltetrazolium bromide (MTT) assay, as previously described [8].

\section{Annexin Staining and FACS Analysis of Apoptosis.}

Apoptosis was detected by annexin staining and flow cytometry as previously described [43] using a BD LSR II flow cytometer and FACS Diva software (BD Biosciences, San Jose, CA; USA). Specific apoptosis was evaluated with the following formula: $100 \times[($ experimental apoptosis \%) - (spontaneous apoptosis of CO \%)] / [100 spontaneous apoptosis of $\mathrm{CO} \%]$.

\section{FACS Analysis of GJIC.}

FACS analysis of GJIC was performed as recently described [30]. In brief, $3 \times 10^{5}$ cells/well in a 6-well plate were labeled for $30 \mathrm{~min}$ at $37^{\circ} \mathrm{C}$ with $3 \mu \mathrm{M}$ Calcein-AM (Acetoxymethyl ester; Merck, Darmstadt; Germany) or $5 \mu \mathrm{M}$ CellTracker Red CMTPX (Invitrogen, Eugene, Oregon; USA) diluted in Opti-MEM medium (Invitrogen). Calcein-loaded donor cells were trypsinized and plated on top of the CellTracker Red-stained acceptor cells at a ratio of $1: 10$. After $6 \mathrm{~h}$ of co-incubation, cells were trypsinized, and single- and double-fluorescent cells were evaluated by FACS analysis.

\section{Colony Forming Assay.}

Three days after siRNA transfection, $1 \times 10^{3} \mathrm{BxPc}-$ 3-GEM cells/well were seeded into 6-well tissue culture plates (BD Falcon ${ }^{\mathrm{TM}}$, San José, CA, USA), and colony forming assays were performed as previously described [44].

\section{The Gemcitabine Bystander Effect.}

Cells were cultured in T75 flasks at concentrations of 4 to $6 \times 10^{6}$ cells per flask. Confluent cells were left untreated or were treated with $3 \mu \mathrm{m}$ gemcitabine for $24 \mathrm{~h}$. Treated cells were mixed at a ratio of 1:1 with untreated cells and were seeded in 6-well plates at a concentration of $7 \times 10^{5}$ cells $/ \mathrm{ml}$. Twenty-four hours later, the cells were trypsinized and seeded at a concentration of $4 \times 10^{4}$ cells/ $\mathrm{ml}$. Next, at 24 or $72 \mathrm{~h}$ after co-cultivation, viability was measured using the MTT assay. Untreated cells were used as a control and set to $100 \%$. To measure GJIC by flow cytometry, untreated cells were stained with CellTracker Red CMTPX (Invitrogen, Eugene, Oregon; USA), cocultured and subjected to annexin staining and FACS analysis of gated CellTracker Red-labeled cells only.

\section{Immunohistochemistry of Established Cell Lines.}

Immunofluorescence staining was performed in established cell lines growing in chambers of the Nunc ${ }^{\circledR}$ Lab-Tek Chamber Slide ${ }^{\text {TM }}$ system (Sigma-Aldrich). According to a standard protocol, 95\% EtOH served as a fixative, and $0.2 \%$ Triton $\mathrm{X}-100$ was used for permeabilization [45]. Nuclei were stained with DAPI (4,6-diamidino-2'-phenylindol, $1 \mu \mathrm{g} / \mathrm{ml}$ ). The binding of primary antibodies was detected using the following secondary Abs: goat anti-rabbit Alexa Fluor 488 IgG, goat anti-rabbit Alexa Fluor 594 IgG, goat anti-mouse Alexa Fluor $594 \mathrm{IgG}$ and goat anti-mouse Alexa Fluor 488 IgG (Invitrogen, Camarillo, CA; USA). Omission of the primary Ab served as a negative control. The signal was detected using a Leica DMRB fluorescence microscope (Leica, Wetzlar; Germany). Images of representative fields were captured using a SPOT ${ }^{\text {TM }}$ FLEX $15.264 \mathrm{Mp}$ shifting pixel digital color camera (Diagnostic, Instruments, Inc. USA) and analyzed with SPOT Basic/Advanced 4.6 software.

\section{Immunohistochemistry of Primary Tissue and Primary Cells.}

Frozen $6-\mu \mathrm{m}$ tissue sections from normal and malignant human pancreas tissue obtained from healthy organ donors, patients with PDA, primary mouse xenografts or spheroidal cultures cytospinned to glass slides were fixed with $4 \%$ paraformaldehyde. Peroxidase activity was blocked with $0.03 \%$ hydrogen peroxide. Immunohistochemistry was performed using EnVision+System-HRP (AEC) (DakoCytomation, Carpinteria, CA; USA). After staining with primary antibodies, the signal was detected as described above for the established cell lines. The omission of the primary Abs was used as a negative control. Patient material was 
obtained under the approval of the ethical committee of the University of Heidelberg. Diagnoses were established by conventional clinical and histological criteria according to the World Health Organization (WHO). All surgical resections were indicated according to the principles and practice of oncological therapy.

\section{siRNA Transfection.}

siRNA against Cx43 (Hs_GJA1_5) was obtained from Qiagen (Maryland; USA), and Mission siRNA Universal Negative Control was purchased from SigmaAldrich (St. Louis, MO; USA). Transfections were performed using the Lipofectamine ${ }^{\mathrm{TM}}$ RNAiMax kit from Invitrogen (Carlsbad, CA; USA) according to the manufacturer's instructions.

\section{Statistical Analysis.}

Data obtained with established and primary cell lines, with the exception of antibody protein arrays, are presented as the mean $\pm \mathrm{SD}$ of at least three separate experiments, performed in triplicates. Statistical significance was evaluated by Student's t-test with Bonferroni correction $(* p<0.05, * * p<0.01)$. Antibody protein arrays were performed twice in duplicates with similar outcome and the means of two experiments are shown.

\section{ACKNOWLEDGEMENTS}

The authors would like to thank G. Moldenhauer for providing mouse $\mathrm{mAb}$ anti-EpCAM and $\mathrm{S}$. Bauer and E. Soyka for excellent technical assistance. This study was supported by grants from the German Cancer Aid (Deutsche Krebshilfe, TF/IH 110079; IH 109362), the German Research Community (DFG HE 3186/11-1), the German Federal Ministry of Education and Research (BMBF 031A213), the German-Israeli Foundation for Scientific Research and Development (GIF 1058-7.11/2008), the Hanns A. Pielenz Stiftung, the Heidelberger Stiftung Chirurgie and the Foundation for Cancer and Scarlet Fever of the University of Heidelberg.

\section{Editorial note:}

This paper acceptance was based in part on peerreview conduced by another journal, revisions and further peer-review by Oncotarget.

\section{STATEMENT OF AUTHOR CONTRIBUTIONS}

TF, VR, YZ, OI, KH, FS, LL, MN, KR, SL, CCN, $\mathrm{JM}, \mathrm{JG}$ - performed the experiments
IH, MS, VR, TF, CG - designed the study

MWB, JW, PS, MMG - provided clinical expertise and discussion of the experiments

TF, MS, IH, VR, LL, CG, KR, WG - analyzed data

$\mathrm{IH}, \mathrm{TF}$ - wrote the paper

\section{ETHICS APPROVAL}

Non-diagnostic patient material was obtained under the approval of the ethical committee of the University of Heidelberg after written informed consent was obtained from patients. Diagnoses were established by conventional clinical and histological criteria according to the World Health Organization (WHO). All surgical resections were indicated according to the principles and practice of oncological therapy.

\section{REFERENCES}

1. Gukovskaya AS, Pandol SJ. Cell death pathways in pancreatitis and pancreatic cancer. Pancreatology. 2004; 4: 567-586.

2. Oberstein PE, Saif MW. First-Line Treatment for Advanced Pancreatic Cancer. Highlights from the "2011 ASCO Gastrointestinal Cancers Symposium”. San Francisco, CA, USA. January 20-22, 2011. Jop. 2011; 12: 96-100.

3. Li C, Heidt DG, Dalerba P, Burant CF, Zhang L, Adsay V, Wicha M, Clarke MF, Simeone DM. Identification of pancreatic cancer stem cells. Cancer Res. 2007; 67: 10301037.

4. Hermann PC, Huber SL, Herrler T, Aicher A, Ellwart JW, Guba M, Bruns CJ, Heeschen C. Distinct populations of cancer stem cells determine tumor growth and metastatic activity in human pancreatic cancer. Cell Stem Cell. 2007; 1: 313-323.

5. Simeone DM. Pancreatic cancer stem cells: implications for the treatment of pancreatic cancer. Clin Cancer Res. 2008; 14: 5646-5648.

6. Herr I, Büchler MW. Dietary constituents of broccoli and other cruciferous vegetables: implications for prevention and therapy of cancer. Cancer Treatment Reviews. 2010; 36: 377-383.

7. Huang J, Plass C, Gerhauser C. Cancer chemoprevention by targeting the epigenome. Curr Drug Targets. 2011; 12: 1925-1956.

8. Kallifatidis G, Rausch V, Baumann B, Apel A, Beckermann BM, Groth A, Mattern J, Li Z, Kolb A, Moldenhauer G, Altevogt P, Wirth T, Werner J, Schemmer P, Büchler MW, Salnikov A, et al. Sulforaphane targets pancreatic tumour-initiating cells by NF-kappaB-induced antiapoptotic signalling. Gut. 2009; 58: 949-963.

9. Zhou W, Kallifatidis G, Baumann B, Rausch V, Mattern J, Gladkich J, Giese N, Moldenhauer G, Wirth T, Buchler MW, Salnikov AV, Herr I. Dietary polyphenol quercetin 
targets pancreatic cancer stem cells. Int J Oncol. 2010; 37: 551-561.

10. Rausch V, Liu L, Kallifatidis G, Baumann B, Mattern J, Gladkich J, Wirth T, Schemmer P, Büchler MW, Zöller M, Salnikov A, Herr I. Synergistic activity of sorafenib and sulforaphane abolishes pancreatic cancer stem cell characteristics. Cancer Res. 2010; 70: 5004-5013.

11. Kallifatidis G, Labsch S, Rausch V, Mattern J, Gladkich J, Moldenhauer G, Büchler MW, Salnikov A, Herr I. Sulforaphane increases drug-mediated cytotoxicity towards cancer stem-like cells of pancreas and prostate. Mol Ther. 2011; 19: 188-195.

12. Herr I, Lozanovski V, Houben P, Schemmer P, Buchler MW. Sulforaphane and related mustard oils in focus of cancer prevention and therapy. Wien Med Wochenschr. 2013; 163: 80-88.

13. Loewenstein WR. Junctional intercellular communication and the control of growth. Biochim Biophys Acta. 1979; 560: 1-65.

14. Trosko JE, Goodman JI. Intercellular communication may facilitate apoptosis: implications for tumor promotion. Mol Carcinog. 1994; 11: 8-12.

15. Warner A. Gap junctions in development--a perspective. Semin Cell Biol. 1992; 3: 81-91.

16. Laird DW. Life cycle of connexins in health and disease. Biochem J. 2006; 394: 527-543.

17. Cottin S, Ghani K, de Campos-Lima PO, Caruso M. Gemcitabine intercellular diffusion mediated by gap junctions: new implications for cancer therapy. Mol Cancer. 2010; 9: 141.

18. Yang L, Chiang Y, Lenz HJ, Danenberg KD, Spears CP, Gordon EM, Anderson WF, Parekh D. Intercellular communication mediates the bystander effect during herpes simplex thymidine kinase/ganciclovir-based gene therapy of human gastrointestinal tumor cells. Hum Gene Ther. 1998; 9: 719-728.

19. Mesnil M, Crespin S, Avanzo JL, Zaidan-Dagli ML. Defective gap junctional intercellular communication in the carcinogenic process. Biochim Biophys Acta. 2005; 1719: 125-145.

20. Trosko JE. The role of stem cells and gap junctional intercellular communication in carcinogenesis. J Biochem Mol Biol. 2003; 36: 43-48.

21. Tai MH, Olson LK, Madhukar BV, Linning KD, Van Camp L, Tsao MS, Trosko JE. Characterization of gap junctional intercellular communication in immortalized human pancreatic ductal epithelial cells with stem cell characteristics. Pancreas. 2003; 26: e18-26.

22. Trosko JE. Gap junctional intercellular communication as a biological "Rosetta stone" in understanding, in a systems biological manner, stem cell behavior, mechanisms of epigenetic toxicology, chemoprevention and chemotherapy. J Membr Biol. 2007; 218: 93-100.

23. Yu SC, Xiao HL, Jiang XF, Wang QL, Li Y, Yang XJ, Ping
YF, Duan JJ, Jiang JY, Ye XZ, Xu SL, Xin YH, Yao XH, Chen JH, Chu WH, Sun W, et al. Connexin 43 reverses malignant phenotypes of glioma stem cells by modulating E-cadherin. Stem Cells. 2012; 30: 108-120.

24. Solan JL, Lampe PD. Connexin43 phosphorylation: structural changes and biological effects. Biochem J. 2009; 419: 261-272.

25. Hwang JW, Park JS, Jo EH, Kim SJ, Yoon BS, Kim SH, Lee YS, Kang KS. Chinese cabbage extracts and sulforaphane can protect $\mathrm{H} 2 \mathrm{O} 2$-induced inhibition of gap junctional intercellular communication through the inactivation of ERK1/2 and p38 MAP kinases. J Agric Food Chem. 2005; 53: 8205-8210.

26. Dovzhanskiy DI, Hartwig W, Lazar NG, Schmidt A, Felix K, Straub BK, Hackert T, Krysko DV, Werner J. Growth inhibition of pancreatic cancer by experimental treatment with 4-phenylbutyrate is associated with increased expression of Connexin 43. Oncol Res. 2012; 20: 103-111.

27. Chen JT, Cheng YW, Chou MC, Sen-Lin T, Lai WW, Ho WL, Lee H. The correlation between aberrant connexin 43 mRNA expression induced by promoter methylation and nodal micrometastasis in non-small cell lung cancer. Clin Cancer Res. 2003; 9: 4200-4204.

28. Sipos B, Moser S, Kalthoff H, Torok V, Lohr M, Kloppel G. A comprehensive characterization of pancreatic ductal carcinoma cell lines: towards the establishment of an in vitro research platform. Virchows Arch. 2003; 442: 444452.

29. Song Y, Washington MK, Crawford HC. Loss of FOXA1/2 is essential for the epithelial-to-mesenchymal transition in pancreatic cancer. Cancer Res. 2010; 70: 2115-2125.

30. Czyz J, Irmer U, Schulz G, Mindermann A, Hulser DF. Gap-junctional coupling measured by flow cytometry. Exp Cell Res. 2000; 255: 40-46.

31. Solan JL, Lampe PD. Key connexin 43 phosphorylation events regulate the gap junction life cycle. J Membr Biol. 2007; 217: 35-41.

32. Solan JL, Hingorani SR, Lampe PD. Changes in connexin 43 expression and localization during pancreatic cancer progression. J Membr Biol. 2012; 245: 255-262.

33. de Feijter AW, Matesic DF, Ruch RJ, Guan X, Chang $\mathrm{CC}$, Trosko JE. Localization and function of the connexin 43 gap-junction protein in normal and various oncogeneexpressing rat liver epithelial cells. Mol Carcinog. 1996; 16: 203-212.

34. Tacheau C, Laboureau J, Mauviel A, Verrecchia F. TNF-alpha represses connexin43 expression in HaCat keratinocytes via activation of JNK signaling. J Cell Physiol. 2008; 216: 438-444.

35. Mesnil M, Krutovskikh V, Piccoli C, Elfgang C, Traub O, Willecke K, Yamasaki H. Negative growth control of HeLa cells by connexin genes: connexin species specificity. Cancer Res. 1995; 55: 629-639.

36. Mehta PP, Bertram JS, Loewenstein WR. Growth inhibition 
of transformed cells correlates with their junctional communication with normal cells. Cell. 1986; 44: 187-196.

37. Hardy TM, Tollefsbol TO. Epigenetic diet: impact on the epigenome and cancer. Epigenomics. 2011; 3: 503-518.

38. Gerhauser C. Epigenetic impact of dietary isothiocyanates in cancer chemoprevention. Curr Opin Clin Nutr Metab Care. 2013; 16: 405-410.

39. Goldberg GS, Moreno AP, Bechberger JF, Hearn SS, Shivers R, D.J. M, Zhang Y-C, Naus CCG. Evidence that disruption of connexon particle arrangements in gap junction plaques is associated with inhibition of gap junctional communication by a glycyrrhetinic acid derivative. Experimental Cell Research. 1996; 222: 48-53.

40. Moldenhauer G, Momburg F, Moller P, Schwartz R, Hammerling GJ. Epithelium-specific surface glycoprotein of $\mathrm{Mr} 34,000$ is a widely distributed human carcinoma marker. Br J Cancer. 1987; 56: 714-721.

41. Lonardo E, Hermann PC, Mueller MT, Huber S, Balic A, Miranda-Lorenzo I, Zagorac S, Alcala S, RodriguezArabaolaza I, Ramirez JC, Torres-Ruiz R, Garcia E, Hidalgo M, Cebrian DA, Heuchel R, Lohr M, et al. Nodal/ Activin signaling drives self-renewal and tumorigenicity of pancreatic cancer stem cells and provides a target for combined drug therapy. Cell Stem Cell. 2011; 9: 433-446.

42. Knapp J, Gross W, Gebhard MM, Schaefer M. Surface contact measurement of electrical cell uncoupling in the mouse heart during ischemia. Bioelectrochemistry. 2005; 67: 67-73.

43. Herr I, Wilhelm D, Bohler T, Angel P, Debatin KM. Activation of CD95 (APO-1/Fas) signaling by ceramide mediates cancer therapy-induced apoptosis. Embo J. 1997; 16: 6200-6208.

44. Apel A, Herr I, Schwarz H, Rodemann HP, Mayer A. Blocked autophagy sensitizes resistant carcinoma cells to radiation therapy. Cancer Res. 2008; 68: 1485-1494.

45. Cottin S, Ghani K, Caruso M. Bystander effect in glioblastoma cells with a predominant cytoplasmic localization of connexin43. Cancer Gene Ther. 2008; 15: 823-831. 